\title{
La figura del Otro como constructor de la imagen y la identidad del sujeto en Platón.
}

The figure of the Other as a constructor of the image and the identity of the subject in Plato.

\author{
Por: Rodriguez, Néstor Emanuel Maximiliano." \\ Universidad Nacional del Nordeste \\ E-mail: rodriguezmaxi55@gmail.com
}

Fecha de recepción: 12/03/2021

Fecha de aprobación: 25/04/2021

DOI: http://dx.doi.org/10.30972/ach.065609

\section{Resumen}

El presente artículo se centra en cómo aparece la figura del Otro (o los otros) en los diálogos platónicos Apología de Sócrates y Critón, y cómo estos dejan ver la problemática de la subjetivación y la formación de la identidad (el yo) de los sujetos (representados aquí por Sócrates y Critón) en base a la presencia de ese Otro que mira y nombra. Por lo tanto, el eje principal de este escrito tiene que ver con cómo influye la presencia del Otro en la conformación de la subjetividad de Sócrates y Critón y cómo estos son vistos de una determinada manera en base a lo que ese Otro deposita en ellos. Es decir; intentar mostrar cómo el Otro percibe al sujeto de una determinada manera y cómo esto, a la vez, termina condicionando e influyendo en el sujeto en el hecho de pensarse y percibirse a sí mismo.

Palabras clave: Sócrates; Critón; Otro; Sujeto; Subjetivación.

\footnotetext{
* Este escrito surge en base al desarrollo de una pasantía en la cátedra Filosofía Antigua.

* Estudiante del Profesorado en Filosofía
} 


\section{Abstract}

This article focuses on how the figure of the Other (or the others) appears in the Platonic dialogues The Apology of Socrates and Crito, and how they reveal the problem of subjectivation and the formation of identity (the self) of the subjects (represented here by Socrates and Crito) based on the presence of that Other who looks and names. Therefore, the main axis of this writing has to do with how the presence of the Other influences the conformation of the Socrates and Crito's subjectivity and how they are seen in a certain way based on what that Other deposits in them. That is to say; try to show how the Other perceives the subject in a certain way and how this, at the same time, It ends up conditioning and influencing the subject in the fact of thinking and perceiving himself.

Key words: Socrates ; Crito ; Other ; Subject ; Subjectivation.

\section{Cómo citar este artículo:}

APA: Rodriguez, N. E. (2021). La figura del Otro como constructor de la imagen y la identidad del sujeto en Platón. Acheronta, № 6, 215-228. Recuperado de: (agregar dirección web)

\section{Introducción}

"El sujeto, o bien se divide a sí mismo o es dividido por los otros.

Este proceso lo objetiva".

Michel Foucault

"De mi otro recibiré toda palabra como un signo de verdad:

y cuando sea yo el que hable, no pondré en duda

que recibe como verdadero lo que diga".

Roland Barthes 
Michel Foucault planteaba que el poder actúa sobre el individuo formando su subjetividad, entendiendo al poder no como un "Poder Soberano" que se ejerce desde una autoridad general hacia un particular sino más bien un poder ejercido entre los propios particulares, o sea, los sujetos ${ }^{1}$. Este poder "categoriza al individuo, le asigna su propia individualidad, lo ata en su propia identidad, le impone una ley de verdad sobre sí que está obligado a reconocer y que otros debe reconocer en él" (Foucault, 2001b, p. 245). Este análisis aborda esta noción de poder, poniendo como eje central a los personajes Sócrates y Critón de los diálogos platónicos Apología de Sócrates y Critón.

Tanto Sócrates como Critón son objetos de la mirada del Otro, influyendo ésta en la constitución de la subjetividad de cada uno y de la imagen que de ellos se tiene. Por el lado de Sócrates, podemos decir que este se forma una identidad gracias a lo que los otros (personalizados en los "primeros y últimos acusadores") dicen de él. Critón, en cambio, actúa en base a esa mirada del Otro por el miedo a que esta misma -así como con Sócrates- forme una imagen errónea de él, motivada por una supuesta traición de Critón hacia Sócrates por no sacarlo de la cárcel.

Por lo tanto, el objetivo central aquí es el de poder entender y analizar estos textos antiguos con términos y conceptos contemporáneos propios de la filosofía y el psicoanálisis, partiendo desde la idea ya mencionada de que es la figura del Otro lo que constituye la subjetivación de un sujeto o, si se quiere, de un yo y mostrar, además, que tanto Sócrates como Critón $-y$ teniendo en cuenta lo planteado por Foucault al comienzo- son categorizados y reconocidos de una determinada manera por la influencia que ejercen los demás sujetos en ellos a través de sus miradas y discursos, generando así una imagen de estos que es adoptada tanto por los otros como por los sujetos mismos (Sócrates y Critón). Imagen, además, que es "perentoria,

\footnotetext{
1 “... por dominación no me refiero al hecho macizo de una dominación global de uno sobre los otros o de un grupo sobre otro, sino a las múltiples formas de dominación que pueden ejercerse dentro de la sociedad: en consecuencia, no al rey en su posición central, sino a los súbditos en sus relaciones recíprocas; no a la soberanía en su edificio único, sino a los múltiples sometimientos que se producen y funcionan dentro del cuerpo social" (Foucault, 2001a, p. 36).
} 
Abril 2021.

tiene siempre la última palabra; ningún conocimiento puede contradecirla, arreglarla, sutilizarla" (Barthes, 2014, p. 172).

\section{Sócrates, la constitución de su imagen y el lugar que ocupan sus acusadores.}

Para comenzar este análisis, es preciso recalcar dos cuestiones básicas; la primera es que el concepto de sujeto que se pretende trabajar aquí es el planteado por la filosofía contemporánea -más precisamente por el posestructuralismo- y la segunda es que lo que caracteriza a este sujeto es el hecho de no ser un sujeto acabado y fijo, sino más bien mutable y subyugado al mundo real y sus relaciones. El sujeto "es en cada momento, producto de acontecimientos (práctico-discursivos) que delimitan y determinan su modo de ser, así como su pensamiento, su expresión y su acción" (Terol Rojo, 2013, p. 279). Teniendo en cuenta esto, si pensamos al sujeto como algo en construcción más que como algo establecido y fijo, en Apología de Sócrates podemos evidenciar esta tesis de una manera muy clara, ya que el sujeto en cuestión (Sócrates) se defiende de la imagen misma que de él se tiene y que fue construida durante toda su vida. Ahora bien, esta imagen no es solo obra de Sócrates y sus acciones, sino que es creada -también- por la mirada que los otros tienen sobre Sócrates. Por lo tanto, es preciso remarcar la importancia que tiene el Otro en la formación de la identidad del sujeto -tanto para sí mismo ${ }^{2}$ como para con los demás- ya que, podemos decir, un sujeto es no solo lo que hace, sino también lo que refleja y el Otro ve en él, es decir, el sujeto también es y se construye gracias a la mirada del Otro. Esto podemos evidenciarlo claramente en otro texto platónico: Alcibíades I. Aquí Platón plantea la idea de que el sujeto se reconoce a sí mismo al verse reflejado en los ojos de un Otro $^{3}$; por lo que, de alguna manera -y hablando en términos contemporáneos-, es el Otro el que posibilita la conformación del sujeto como tal (o lo que en términos platónicos

\footnotetext{
2 "No sé atenienses, la sensación que habéis experimentado por las palabras de mis acusadores. Ciertamente, bajo su efecto, incluso yo mismo he estado a punto de no reconocerme; tan persuasivamente hablaban" (Apol. 17a).

3 "¿Has observado, entonces, que el rostro de quien mira fijamente a los ojos se deja ver como en un espejo en la mirada de quien lo enfrenta, y le llamamos precisamente pupila, puesto que es como una imagen de quien mira al rostro?" (Alc. 132e-133a).
} 
podemos denominar como "lograr el conocimiento de sí mismo"”), funcionando como espejo. De esta manera, el sujeto se reconoce como tal gracias a un Otro que observa.

En Apología de Sócrates podemos evidenciar dos maneras de presentarse la figura del Otro-que-mira en tanto constitución del sujeto en lo que Platón denomina como "primeros acusadores" y "segundos -o últimos- acusadores" ${ }^{5}$. A los primeros acusadores podemos definirlos como una entidad abstracta que condiciona y delimita a Sócrates como un sabio "que se ocupa de las cosas celestes, que investiga todo lo que hay bajo la tierra y hace más fuerte el argumento más débil” (Apol. 18b-c). La característica principal de estos primeros acusadores es que, como ya dijimos, debido al paso del tiempo se volvieron abstractos, ya no son sujetos-que-hablan sino que solo son eso que se habló, es decir, un discurso. Los sujetos concretos desaparecen pero la mirada y el discurso de esos sujetos (los otros) perduraron en tanto constituyen la imagen que se tiene de Sócrates a la hora del juicio; sobre esto Platón escribe: "lo más absurdo de todo es que ni siquiera es posible conocer y decir sus nombres" (Apol. 18b). Lo que Sócrates nos dice respecto a estos es que fueron construyendo una imagen de él que poco a poco toda la ciudad fue adaptando, por lo que $-\mathrm{y}$ volviendo a lo planteado al principio- podemos decir que la imagen de Sócrates no es solo obtenida gracias a Sócrates cual reflejo en absoluta soledad frente a un espejo, sino que más bien es también influenciada por la mirada del Otro y lo que este dice. Opinión que tiene su causa en la supuesta sabiduría de Sócrates, tal como dice Platón cuando escribe que "yo [Sócrates] no he adquirido este renombre por otra razón que por cierta sabiduría. ¿Qué sabiduría es esa? La que, tal vez, es sabiduría propia del hombre" (Apol. 20d) y que "ha servido de caldo de cultivo para la creación de nuevas y numerosas enemistades, y para el surgimiento de las tergiversaciones en torno a su presunta sabiduría" (Soares, 2010, p. 35).

\footnotetext{
4 “Un ojo entonces contemplando a un ojo, y dirigiendo la mirada hacia lo que es lo óptimo de él y con lo que ve: así se conocería a sí mismo" (Alc. 133a).

5 "En efecto, admitid también vosotros, como yo digo, que ha habido dos clases de acusadores míos: unos, los que me han acusado recientemente, otros, a los que ahora me refiero que me han acusado desde hace mucho, y creed que es preciso que yo me defienda frente a éstos en primer lugar. Pues también vosotros les habéis oído acusarme anteriormente y mucho más que a estos últimos" (Apol. 18d-e).
} 
Por otro lado, al hablar de los segundos o últimos acusadores, a diferencia de los primeros, podemos decir que estos sí poseen una corporalidad y una realidad, ya que se ven representados por tres figuras: Ánito, Licón y Meleto ${ }^{6}$. Estos acusan a Sócrates de corromper a la juventud y de no creer en los dioses de la ciudad, instaurando nuevas divinidades. Teniendo en cuenta esto, vale aclarar que no es preciso de este escrito hablar sobre cada una de estas acusaciones ${ }^{7}$, sino más de bien de cómo estas actúan sobre Sócrates y los ciudadanos.

\section{1. El Otro activo.}

La mirada del Otro actúa, no es pasiva. Desde los primeros acusadores hasta los últimos, la imagen que el Otro devolvía de Sócrates es considerada la imagen verdadera de este. El Otro no ve a Sócrates, sino que ve de Sócrates. Ve de Sócrates lo que se constituyó alrededor de su figura. De esta manera, las acciones propias de Sócrates tienen poca relevancia al enfrentarse a la mirada del Otro, ya que este ve lo que ya desde los primeros acusadores se intentó instaurar sobre Sócrates, por lo que podemos decir que lo que Sócrates es, no es más que lo que el Otro pone en él; de manera que para ser y tener una identidad, necesitó de Otro que lo mire y lo nombre

Ahora bien, podemos tomar a Sócrates como señuelo para una teoría más compleja. De esta manera, Sócrates representaría al sujeto en sí mismo. Este sujeto 1) está en constante construcción y 2) es y está con otros, por lo que lo que el sujeto llega a ser es en parte también obra de lo que el Otro deposita en él. El sujeto no es sin un Otro, el sujeto es gracias a un Otro. Asimismo, el Otro guía el camino en la medida en que su mirada es dirigida hacia el sujeto que actúa, y este sujeto -a la vez- se acomoda a las demandas de ese Otro, sobre esto Bourdieu (2015) escribe que "los individuos o los grupos son definidos no solamente por lo que son, sino también por lo que tienen la reputación de ser, por un ser percibidos" (p. 217). De esta manera, el sujeto si quiere constituirse como tal debe -necesariamente- adaptarse a lo que el Otro -o los otros-

\footnotetext{
6 “Como consecuencia de esto me han acusado Meleto, Ánito y Licón; Meleto, irritado en nombre de los poetas; Ánito, en el de los demiurgos y de los políticos; y Licón, en el de los oradores" (Apol. 23e-24a).

7 "Sócrates comete delito y se mete en lo que no debe al investigar las cosas subterráneas y celestes, al hacer más fuerte el argumento más débil y al enseñar estas mismas cosas a otros" (Apol. 19b-c).
} 
demandan de él ${ }^{8}$. El sujeto -o el yo- no es más que el Otro devenido subjetividad. La reputación de Sócrates no es más que el Otro devenido opinión. Por lo tanto, la condena que sufre Sócrates no es debido solo a él en tanto sujeto constituido por sí mismo, sino también en tanto sujeto constituyente y receptor del peso de la mirada y el discurso del Otro en él; tal como lo expresa Platón en el siguiente párrafo:

Lo que yo decía antes, a saber, que se ha producido gran enemistad hacia mí por parte de muchos, a sabed bien que es verdad. Y es esto lo que me va a condenar, si me condena, no Meleto ni Ánito, sino la calumnia y la envidia de muchos (Apol. 28a).

\section{Critón y el temor al discurso del Otro. Análisis del proceso de subjetivación $y$ conformación del yo.}

El texto platónico llamado Critón se centra en el diálogo imaginario que tiene Sócrates con "Las Leyes" después de que su amigo Critón le proponga escapar de la cárcel donde espera la llegada de la nave de Delos para luego morir envenenado por beber la famosa cicuta, de esta manera "todo el Critón, en efecto, gira en torno a la discusión acerca de si es justo o no escapar de la prisión y salvarse de la condena a muerte asignada por los jueces del tribunal" (Soares, 2010, pp. 50-51). Teniendo en cuenta esto, la idea en la que nos enfocaremos aquí no es la obediencia o no a las leyes ni la espera de la muerte de Sócrates, sino que el tema central pasará por el personaje Critón y la influencia que tiene la mirada y el discurso del Otro en él y en sus acciones constituyendo -o pretendiendo constituir- así su subjetividad consigo mismo y la visión que de él tienen los demás, generando así, como lo plantea el título de este apartado, un temor hacia el discurso y la mirada de ese Otro. Temor, asimismo, que hace surgir la

\footnotetext{
${ }^{8}$ Para entender esta idea podemos poner como ejemplo la idea planteada por Freud en El creador literario y el fantaseo. Aquí, este explica que el niño puede jugar sin la presión de la mirada del otro, en cambio el sujeto adulto -a diferencia del niño- no puede (ni debe) jugar y debe esconder sus fantasías porque "este sabe lo que de él esperan" (Freud, 1992a, p. 129); por lo que de alguna manera debe reprimirse, o más bien, comprimirse para encajar en los espacios que el otro establece y otorga. Por lo tanto, para convivir con los otros, el sujeto debe amoldarse a lo que esos otros esperan de él. El sujeto debe ser según los parámetros de los otros.
} 
Abril 2021.

cuestión de si Critón quiere ayudar a Sócrates por ser su amigo o más bien por el malestar que genera este temor y el qué dirá el Otro.

\subsection{La opinión de la mayoría y la imagen de Critón.}

Teniendo en cuenta la noción de sujeto presentada al comienzo del escrito (es decir, entenderlo como algo en constante cambio y devenir más que como algo ya establecido) y llevándolo al plano literario de Platón, podemos entender y analizar a Critón como un personaje que está arrojado en un determinado contexto social y político en relación con otros sujetos-personajes que podemos denominar "la gente" o "la mayoría". Esta "mayoría", en el Critón, actúa como un tercer personaje que se da entidad a sí mismo a través de las vacilaciones de Critón, rige el comportamiento de este y llama la atención de Sócrates. La mayoría se vuelve una entidad abstracta que forma y reforma la subjetividad y la idea que tienen de Critón tanto los demás como él mismo ${ }^{9}$.

Critón se acerca hacia el lugar donde Sócrates espera la hora de morir para ofrecerle (rogarle) a este que acepte su propuesta de escapar de la cárcel. Ahora ¿por qué Critón se muestra tan empeñado en que Sócrates escape de la cárcel y salve su vida? Él le ofrece como argumento el hecho de que si Sócrates no escapa estaría dejando huérfanos a sus propios hijos, traicionándolos y sin terminar de instruirlos en lo que es justo ${ }^{10}$; pero, siguiendo la línea de nuestra investigación, quizá el verdadero motivo de Critón está en la opinión y el "poder de la mayoría" ${ }^{11}$. Si está interesado en salvar a Sócrates no lo sabemos pero lo que sí es preciso recalcar es que, para él, si Sócrates no se salva, la mayoría verá en Critón a una persona que, teniendo mucho dinero, no lo puso a disposición para salvar a su amigo, como lo escribe Platón en el siguiente pasaje:

\footnotetext{
9 Tal como se evidencia ya en Apología de Sócrates y los "primeros acusadores".

10 "Además, me parece a mí que traicionas también a tus hijos; cuando te es posible criarlos y educarlos, los abandonas y te vas, y, por tu parte, tendrán la suerte que el destino les depare, que será, como es probable, la habitual de los huérfanos durante la orfandad. Pues, o no se debe tener hijos, o hay que fatigarse para criarlos y educarlos. Me parece que tú eliges lo más cómodo" (Critón, 45c-d).

11 “Pero ves, Sócrates, que es necesario también tener en cuenta la opinión de la mayoría. Esto mismo que ahora está sucediendo dejar ver, claramente, que la mayoría es capaz de producir no los males más pequeños, sino precisamente los mayores, si alguien ha incurrido en su odio" (Critón, 44d).
} 
(...) querido Sócrates, todavía en este momento, hazme caso y sálvate. Para mí, si tú mueres, no será una sola desgracia, sino que, aparte de verme privado de un amigo como jamás encontraré otro, muchos que no nos conocen bien a ti y a mí creerán que, habiendo podido yo salvarte, si hubiera querido gastar mi dinero, te he abandonado. Y, en verdad, ¿̇hay reputación más vergonzosa quela de parecer que se tiene en más al dinero que a los amigos? (Critón, 44b-c).

Ahora, teniendo en cuenta esto, podemos interpretar a Critón como un personaje egoísta y preocupado por sí mismo o también como un sujeto abrumado por el poder que ejerce la mirada del Otro en la conformación que se tiene de la propia subjetividad y de la imagen de sí que tienen los demás.

\subsection{El Otro, el yo y la subjetivación de Critón ${ }^{12}$.}

Leonardo Peskin (2009), en un artículo titulado El yo, el objeto y el otro nos dice que "el otro es el correlato permanente del funcionamiento yoico, en el otro el yo se reconoce y plantea su dramática monótona de completamiento o desmoronamiento" (p. 82-83). Critón se ve y se reconoce a sí mismo en el Otro, en la mayoría. Se reconoce como una persona que, teniendo dinero, no ayudó a su amigo y a la vez teme que este Otro, la mayoría, lo reconozcan de la misma manera (esto si Sócrates no se escapa), tal como escribe Lacan (2009) cuando dice que "el deseo del hombre encuentra su sentido en el deseo del otro, no tanto porque el otro guarda las llaves del objeto deseado, sino porque su primer objeto es ser reconocido por el otro" (p. 259). A diferencia de la Apología de Sócrates ${ }^{13}$, en Critón los hechos -y dichos- de los que se

\footnotetext{
${ }^{12}$ Es importante remarcar aquí que se utilizan también conceptos extraídos del psicoanálisis; disciplina que trabaja profundamente la cuestión de la constitución del yo en los sujetos y como este se desarrolla en base a un Otro. Tal es el caso, por ejemplo, de textos como El estadio del espejo como formador de la función de yo [je] tal como se nos revela en la experiencia psicoanalítica de Jacques Lacan (2009) y EI sepultamiento del complejo de Edipo de Sigmund Freud (1992b) donde el sujeto es y se constituye mediante un Otro, que en estos casos, es el Otro como función-padre o función-madre.

${ }^{13}$ Teniendo en cuenta lo dicho anteriormente, las razones que podríamos ocupar para entender que lo que Sócrates es en tanto sujeto está influenciada por las opiniones empíricas de los otros, donde hay acusaciones llevadas hasta el juicio -a excepción de la ya mencionada opinión de los "primeros acusadores"-. En cambio, en Critón la influencia del Otro hace referencia más a una posible acusación que se daría sobre Critón que sobre acusaciones verdaderas. Aquí la influencia del Otro es en el plano de lo posible pero que aun así determina el proceso de subjetivación de Critón que, atento al "poder de la
} 
Abril 2021.

inquieta nuestro personaje aún no ocurren y solo son proyecciones de él mismo en los otros, pero de todas formas queda evidenciado cómo la mirada del Otro condiciona la forma de pensarse a sí mismo, es decir, condiciona y/o influye en el proceso de subjetivación y, volviendo a lo planteado al comienzo, siendo el ser humano un ser mutable y no un ser acabado, el discurso y la mirada del Otro es un factor clave para la conformación del sujeto. Critón no solo es lo que es y lo que hace, sino que también es -o puede ser- lo que los demás dicen y hacen de él, el discurso del Otro lo atraviesa completamente condicionando hasta la forma de conocerse, denominarse y nombrarse a sí mismo ya que el sujeto y sus acciones no son "puras" sino que aparecen nombradas -por sí mismo y por un otro-, tal como escriben Gutiérrez y Zapico (2018) cuando afirman que:

La opinión que agregamos a los hechos objetivos es considerada como la fuente de perturbación del humano, porque lo aleja de los instrumentos naturales que posee para percibir lo conveniente para sí mismo, en tanto que esta proviene de las percepciones personales del vulgo (pp. 86-87).

Similar a lo que Critón le plantea a Sócrates cuando dice que "la mayoría no llegará a convencerse de que tú mismo no quisiste salir de aquí, aunque nosotros nos esforzábamos en ello" (Critón, 44c).

\subsection{Lo irascible en Critón. El reconocimiento y la vergüenza.}

Volviendo al plano puramente platónico, este miedo de Critón respecto a la mirada y opinión del Otro se puede comparar también con la psicología planteada por este autor y su tripartición del alma, consistiendo ésta en que el alma posee tres partes que lo conforman: la parte racional (tò logistikón) con la cual se piensa, la parte apetitiva (tò epithymetikón) que corresponde a los placeres y la parte irascible (tò thymoeidés) con la cual el ser humano es fogoso y tiende al reconocimiento. Platón refleja esto en la siguiente cita:

mayoría" pretende salvar a Sócrates para también él no ser subjetivado por los demás como alguien que teniendo dinero, no ayudó a su amigo. 
En cambio, resulta difícil darse cuenta si en todos los casos actuamos por medio de un mismo género, o bien si, por ser tres los géneros, en un caso obramos por medio de uno de ellos, en otro por medio de otro. Por ejemplo: por medio de uno de estos géneros que hay en nosotros aprendemos, por medio de otro somos fogosos $y$, a su vez, por el tercero deseamos los placeres relativos a la alimentación, a la procreación y todos los similares a ellos (Rep. IV, 436a-b).

Ahora, como plantea Modenutti (2019) "es preciso considerar que la vergüenza también procede de la parte timócrata o irascible del alma que, preocupada por la fama y los honores, teme frente a la desaprobación social de sus acciones" (p. 129), por lo tanto, la parte irascible del alma se corresponde con las ansias de veneración y reconocimiento, es decir, las ansias de ser mirado (de buena manera) por un Otro. Teniendo en cuenta esto, podríamos decir que es esta parte del alma la que gobierna en Critón, donde el reconocimiento que le puede llegar a dar la mirada del Otro en base a lo que haga o no con Sócrates es su preocupación principal. Es la parte irascible la que lo gobierna y lo lleva a actuar, primando así su proceso de subjetivación y la idea que de él se tiene por sobre todas las demás cosas, retornando así a lo ya planteado al comienzo: Critón pretende que Sócrates escape no por Sócrates en sí y su integridad, sino por la reputación que caería sobre Critón si este no huye y la vergüenza que sentiría, pero no por ser egoísta -o quizá sí, no lo sabemos- sino por el gran poder que posee la mayoría y la influencia que ejerce su mirada en los sujetos y su subjetividad; tal como se evidencia a continuación:

Así que yo siento vergüenza, por ti y por nosotros tus amigos, de que parezca que todo este asunto tuyo se ha producido por cierta cobardía nuestra: la instrucción del proceso para el tribunal, siendo posible evitar el proceso, el mismo desarrollo del juicio tal como sucedió, y finalmente esto, como desenlace ridículo del asunto, y que parezca que nosotros nos hemos quedado al margen de la cuestión por incapacidad y cobardía, así como que no te hemos salvado ni tú te has salvado a ti mismo, cuando era realizable y posible, por pequeña que fuera nuestra ayuda. Así pues, Sócrates, que esto además del daño, no sea vergonzoso para ti y para nosotros (Critón, 45e-46a). 
Cabe recalcar, además, que con esta ansia de reconocimiento Critón teme ser visto como un mal amigo pero, a la vez, desea el reconocimiento de ser visto como uno bueno si lo ayuda a escapar; por lo que podemos decir que la mirada del Otro en el proceso de subjetivación posee una doble vara moral donde la imagen que el Otro proyecta del sujeto es considerada buena por este si la misma le otorga honores y reconocimientos, y mala si lo que genera es rechazo y deshonra (idea similar que también está presente en el discurso de Fedro en Banquete, donde este plantea que es la vergüenza y el deseo de honor lo que debe guiar la vida de las personas ${ }^{14}$ ).

\section{Conclusión.}

En síntesis, podemos decir que tanto Sócrates como Critón, son un reflejo a des-tiempo del sujeto contemporáneo, es decir, un sujeto absolutamente condicionado por un Otro y un poder que disciplina y condiciona ${ }^{15}$. El sujeto contemporáneo, como ya dijimos, es un sujeto en construcción y debe gran parte de esa construcción a la influencia que el Otro ejerce sobre él. Es a través del discurso y de la mirada de un Otro que el yo se va conformando como tal, sean estas explícitas o implícitas, tal es el caso de Sócrates en el que lo que se ve de él es debido a una reputación que empieza en Sócrates y sus acciones y termina en el Otro devolviendo una imagen de este y esas acciones, imagen que va constituyendo así la identidad de Sócrates en los demás y en sí mismo.

\footnotetext{
14 "Lo que, en efecto, debe guiar durante toda su vida a los hombres que tengan la intención de vivir noblemente, esto, ni el parentesco, ni los honores, ni la riqueza, ni ninguna otra cosa son capaces de infundirlo tan bien como el amor. ¿Y qué es esto que digo? La vergüenza ante las feas acciones y el deseo de honor por lo que es noble, pues sin estas cualidades ni una ciudad ni una persona particular pueden llevar a cabo grandes y hermosas realizaciones" (Banq. 178c-d).

15 "No hay que concebir al individuo como una especie de núcleo elemental, átomo primitivo, materia múltiple e inerte sobre la que se aplica y contra la que golpea el poder, que somete a los individuos y los quiebra. En realidad, uno de los efectos primeros del poder es precisamente hacer que un cuerpo, unos gestos, unos discursos, unos deseos se identifiquen y se constituyan como individuos. Vale decir que el individuo no es quien está enfrente del poder; es, creo, uno de sus efectos primeros. El individuo es un efecto del poder y, al mismo tiempo, en la medida en que lo es, es su relevo: el poder transita por el individuo que ha construido" (Foucault, 2001a, p.38).
} 
Por el lado de Critón, podemos notar que se ve a sí mismo según la idea que él tiene sobre lo que el Otro ve en él, generando así una relación casi abstracta pero relación en fin. Critón se ve a sí mismo como se ve porque sabe que existe un Otro que también lo observa, y actúa en base a ese Otro, ve en él un espejo en el cual reconocerse. La parte irascible del alma, el ansia de reconocimiento y el tratar de evitar la vergüenza, guían su conducta; poniendo por delante la imagen que el Otro le devuelve -o cree que le devuelve- como base para actuar y así, en este caso, ayudar a Sócrates; quizá en parte porque es su amigo, pero en otra porque está y sabe que está totalmente condicionado por el poder que tiene la mayoría sobre su subjetivación y su reputación. Porque si algo al parecer sabe y es consciente Critón es de que el Otro existe, y que él es en relación con ese Otro, por lo que todo lo que hace es en base a esa relación imposible de eliminar que hay entre sujeto-Otro, ya que no hay yo sin un Otro y no hay Otro si no soy consciente de su influencia.

\section{Bibliografía:}

- Barthes, R. (2014). Fragmentos de un discurso amoroso. (E. Molina, Trad.). Argentina: Siglo XXI editores.

- Bourdieu, P. (2015). El sentido práctico. (A. Dilon, Trad.). Buenos Aires, Argentina: Siglo XXI editores.

- Foucault, M. (2001a). Defender la sociedad. Buenos Aires, Argentina: FCE.

- Foucault, M. (2001b). El sujeto y el poder. En: Dreyfus, H. y Rabinow, P. Michel Foucault: más allá del estructuralismo y la hermenéutica. Buenos Aires: Ediciones Nueva Visión.

- Freud, S. (1992a). El creador literario y el fantaseo. En: Obras Completas. Tomo IX. Buenos Aires: Amorrortu editores.

- Freud, S. (1992b). El sepultamiento del complejo de Edipo. En: Obras completas. Tomo XIX. Buenos Aires: Amorrortu editores. 
Abril 2021.

ISSN 2344-9934

- Gutiérrez, M. E. J. \& Zapico, M. G. (2018). Epicureísmo y Foucault: El poder sobre uno mismo y el poder sobre los demás. Thémata. $\mathrm{N}^{\circ} 57$, pp.: 81-94.

- Lacan, J. (2009). Escritos I. (T. Segovia, Trad.). Mexico: Siglo XXI editores.

- Modenutti, C. (2019). El eros de Alcibíades. Entre Sócrates y la philotimia. Nuevo Itinerario, 14 (1), 111-137.

- Peskin, L. (2009). El yo, el objeto y el otro. Revista Uruguaya de Psicoanálisis. № 108, pp.: 67-89.

- Platón (2010). Apología de Sócrates. (J. Calonge, Trad.). En: Platón I. Colección Grandes Pensadores. España: Gredos.

- Platón (2010). Banquete. (M. Martínez, Trad.). En: Platón I. Colección Grandes Pensadores. España: Gredos.

- Platón (2010). Critón. (J. Calonge, Trad.). En: Platón I. Colección Grandes Pensadores. España: Gredos.

- Platón (2013). Alcibíades. (O. Velásquez, Trad.). Santiago de Chile: Ed. Tácitas.

- Platón (2014). República (C. Eggers Lan, Trad.). En: Platón II. Colección Grandes Pensadores. España: Gredos.

- Soares, L. (2010). Platón y la política. España: Tecnos.

- Terol Rojo, G. (2013). Lecturas de la crítica foucaultiana a la subjetividad. Thémata. $\mathrm{N}^{\circ}$ 47, pp.: 273-300. 